\title{
Influences of word predictability and type of masker noise on intelligibility of sung text in live concerts
}

Link to publication record in Manchester Research Explorer

\section{Citation for published version (APA):}

Heinrich, A., Knight, S., \& Hawkins, S. (2015). Influences of word predictability and type of masker noise on intelligibility of sung text in live concerts. The Journal of the Acoustical Society of America, 138(4), 2373-2386.

\section{Published in:}

The Journal of the Acoustical Society of America

\section{Citing this paper}

Please note that where the full-text provided on Manchester Research Explorer is the Author Accepted Manuscript or Proof version this may differ from the final Published version. If citing, it is advised that you check and use the publisher's definitive version.

\section{General rights}

Copyright and moral rights for the publications made accessible in the Research Explorer are retained by the authors and/or other copyright owners and it is a condition of accessing publications that users recognise and abide by the legal requirements associated with these rights.

\section{Takedown policy}

If you believe that this document breaches copyright please refer to the University of Manchester's Takedown Procedures [http://man.ac.uk/04Y6Bo] or contact uml.scholarlycommunications@manchester.ac.uk providing relevant details, so we can investigate your claim.

\section{OPEN ACCESS}




\title{
Influences of word predictability and type of masker noise on intelligibility of sung text in live concerts
}

\author{
Antje Heinrich, ${ }^{1, a)}$ Sarah Knight, ${ }^{1}$ and Sarah Hawkins ${ }^{2}$ \\ ${ }^{1}$ MRC Institute of Hearing Research, Nottingham, NG7 2RD, United Kingdom \\ ${ }^{2}$ University of Cambridge, Faculty of Music, Cambridge, CB3 9DP, United Kingdom
}

(Received 12 January 2015; revised 29 July 2015; accepted 17 August 2015; published online 23 October 2015)

\begin{abstract}
Vocal music is often intended to convey meaning, but how effectively this is achieved is poorly understood. This study systematically assessed the influence of three non-phonetic factors on the intelligibility of sung words in six public concerts in different venues: word predictability from sentence context, type of masker noise (spoken babble, sung vowels, $\left[\int^{\mathrm{w}}\right]$ ), and signal-to-noise ratio (SNR). Stimuli were sung live by a professional a cappella ensemble with one male singing target sentences and five others (two female) producing the masker sounds. The concert audiences $(N=319)$ reported the final word of each sentence using a handheld voting device, from four phonetically- and semantically-controlled written alternatives projected onto a screen after the sentence was sung. Although overall accuracy differed between performances, intelligibility patterns were robust across concerts. They included predicted main effects of masker noise type ( $\left[\int^{\mathrm{w}}\right]$ masking least disruptive, babble most), SNR (high $>$ low), semantic predictability (high $>$ low), listener age (young $>$ old), and listener language status (native $>$ non-native), and some strong interactions. These results suggest that, despite acoustic differences between sung and spoken words and the unusual and varied experimental venues, key findings from traditional speech research apply to sung words, given appropriate musical composition.

(C) 2015 Author(s). All article content, except where otherwise noted, is licensed under a Creative Commons Attribution 3.0 Unported License. [http://dx.doi.org/10.1121/1.4929901]
\end{abstract}

$[\mathrm{TCB}]$

Pages: 2373-2386

\section{INTRODUCTION}

Much music is song, and songs usually have words that convey meaning. However, the relevant sung text is often presented in competition with other sounds, such as instruments and backing singers, a circumstance that may reduce the intelligibility of the sung message. This issue can be particularly acute when maintaining a constant timbre is highly valued, as in Western classical singing, the subject of this study. Investigations of the intelligibility of sung text are few, and those which do exist have mainly focused on the perception of words in carrier phrases (Collister and Huron, 2008; Johnson et al., 2014) or of isolated vowels (Benolken and Swanson, 1990; Hollien et al., 2000; Gregg and Scherer, 2006) sung in a quiet background.

Much more is known about factors governing the intelligibility of speech, and the question arises whether we can apply principles that govern speech intelligibility to singing. However, caution is warranted when generalising from speech to singing because critical temporal and spectral characteristics differ between the two due to the specific musical demands of singing. Examples are the subjugation of speech rhythm to musical rhythm (Burleson, 1992) and deliberate shaping of the vocal tract so as to enhance certain frequencies in the glottal spectrum in order to achieve particular effects of timbre (Sundberg, 1975; Carlsson and Sundberg, 1992) or audibility (Smith and Wolfe, 2009). Such modifications distort the formant structure typical of

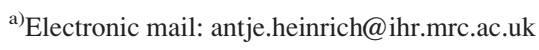

spoken vowels, making the vowels less intelligible (Scotto di Carlo and Germain, 1985; Hollien et al., 2000; Joliveau et al., 2004; Smith and Wolfe, 2009). A further contrast between speech and singing is that in ensemble singing, "background noise" is intentionally intrinsic to the signal, and may contribute to the message; this is not usually the case with speech. Given these differences between speaking and singing it is unclear if and to what extent experimental data on speech will apply to singing. In particular, no one has tested intelligibility of sung words in a normally-varying range of meaningful sentences, a listening situation that is similar to that of listeners following a typical song. To the extent that words heard earlier in a sentence increase the predictability of words later in the sentence, the intelligibility of final target words should be relatively good, given reasonable basic intelligibility.

The present experiment applied three robust nonphonetic influences on speech intelligibility to text sung by one tenor in live concert settings. These influences were word predictability, type of masker noise, and signal-tonoise ratio (SNR). Word predictability was examined using a variant of the revised speech-perception-in-noise (R-SPIN) test. Three types of masker noise were used: multi-talker spoken babble, multiple simultaneous sung vowels (emulating material with some sub-lexical content), and English "sh" $\left[\int^{\mathrm{w}}\right]$. Each masker noise type was produced by five other singers (two women), loudly and softly, to create a relatively low or high SNR with the target voice.

The interfering effects of masker sounds are often described in terms of energetic and informational masking. 
Intelligibility losses due to energetic masking result from physical overlap in neural excitation caused by noise and target, and thus incomplete coding of the signal on a neuronal level. Intelligibility losses due to informational masking result less from incomplete coding and more from listeners' inability to segregate target speech from similar-sounding interfering speech; specific influences may include attentional capture, semantic interference, and generally increased cognitive load (Kidd et al., 1998; Brungart, 2001). Of the three masker noises used in this study, spoken babble was expected to provide both energetic and informational masking, the sung vowels considerable energetic but little or no informational masking, and $\left[{ }^{\mathrm{w}}\right]$ some energetic masking and essentially no informational masking. Putative influences due to interfering pitches were expected to be pronounced for sung vowels, since the masker vowels were sung on pitches in close harmony with the pitch range of the target sentence.

This study also addressed the question of how reproducible results are across live performances in different environments. Our approach contrasts sharply with the normal practice of experimental research where pre-recorded stimuli are presented in acoustically well-controlled testing environments. In contrast, performing musicians typically give live performances in which sung words are produced without the chance for correction, delivered in venues with widely varying acoustic characteristics, and listened to by diverse audiences. In order to make the results useful for performing musicians, it is important to assess the stability of result patterns across different performance situations. We therefore performed the same test with different sentence-by-condition combinations across different concert settings and audiences and assessed how robust an observed effect is to changes in conditions. This procedure had the additional practical advantage of keeping each performance to an acceptable duration.

Because it is well understood how speech intelligibility is affected by variables such as listener age (Pichora-Fuller et al., 1995; Pichora-Fuller, 2003), listener language status (LS) (Mayo et al., 1997; van Wijngaarden et al., 2002), various masker sounds (Rosen et al., 2013), and response modality (Clopper et al., 2006), we had a broad basis from which to link the current study using sung sentences to similar conditions tested in laboratory-based speech research. Hypotheses were formulated based on these previous studies, which show that: high-predictability sentences are more intelligible than low-predictability sentences (Kalikow et al., 1977; Bilger et al., 1984); informational masking reduces intelligibility more than energetic masking (Hoen et al., 2007; Rosen et al., 2013); higher SNRs are less detrimental to intelligibility than lower SNRs, and word predictability is less influential at higher SNRs (Miller et al., 1951; Tun and Wingfield, 1999; Wilson et al., 2012); older listeners tend to perform worse than younger listeners but may benefit more from supportive context than younger listeners (Pichora-Fuller et al., 1995; Pichora-Fuller, 2003) [although not replicated by GordonSalant and Fitzgibbons (1997)]; and non-native listeners perform less well than native listeners and gain less benefit from supportive context (Mayo et al., 1997; van Wijngaarden et al., 2002). If listening to sung words is subject to the same general semantic and noise influences as listening to spoken words, results for these non-phonetic parameters in singing should mirror those for speech.

The music used in the current study was composed in a contemporary Western Classical style, using simple rhythms and a small melodic range. The Western Classical style was chosen because the composer and professional vocal ensemble asked us to collaborate with them in exploring intelligibility of sung text, and the style well exemplifies some of the ways in which sung words can differ from spoken words. For instance, this style can result in distorted vowel sounds due to the focus on maintaining an artificially constant timbre. Another typical characteristic is the simultaneous singing of multiple texts, as in Medieval motets or operatic arias involving multiple characters. Nevertheless, challenges around text intelligibility exist in other vocal musical traditions as well, and we hope that the findings will contribute to a wider discussion of intelligibility in singing.

\section{METHODS}

The experiment was part of a 50-min work for six solo voices (Tales from Babel), which tells a comic story about a suburban garden party attended by various characters. During Tales from Babel, concert-style ensemble performances are interspersed with interactive tests, with slight variations in the parts presented to suit the audience and event. At all concerts, which took place during 2013, the work was performed by members of The Clerks, a professional British vocal ensemble.

\section{A. Overview of test design and task}

The test consisted of sentences sung solo by a tenor, either in quiet or at the same time as the other five singers (two female) were producing one of three types of masker noise: spoken babble, sung vowels, and the fricative $\left[\int^{\mathrm{w}}\right]$. Of ten pairs of test sentences (Table I), four pairs were heard only in quiet $(Q 1-Q 4)$, and six pairs in each type of noise, but not in quiet $(N 1-N 6)$. In all cases the onset and offset of the masker noise coincided with those of the target sentence. Masker noise level was either high (loud) or low (soft) throughout the sentence, corresponding, respectively, to low and high SNRs. For simplicity and clarity, the term "SNR" will be used throughout to refer to masker noise level, although it must be remembered that these levels were not strictly controlled due to the live nature of the performance.

The test sentences were taken from a previous study (Heinrich et al., 2011) and comprised pairs of sentences contrasting in predictability of the last word, which functioned as the target word and had either high predictability (HP) or low predictability (LP). Each sentence pair shared the same last (target) word, but differed in the preceding words of the sentence (the precursor), thereby affecting target word predictability. In a four-alternative forced-choice task, listeners identified the last (target) word of each sentence. After a sentence was sung, its target word and three phonetically- and semantically-controlled foil words (Table I) were projected onto a screen, randomly ordered, and numbered 1-4. 
TABLE I. Sentence pairs and foils. ID: $P 1-P 4$ : practice sentences heard in quiet $(P 1)$, babble $(P 2)$, $\left[\int^{\mathrm{w}}\right](P 3)$, and vowel masker $(P 4)$. $Q 1-Q 4$ : test sentence pairs heard in quiet. N1-N6: test sentence pairs heard in masker noise (babble, vowels, [ $\left.{ }^{\mathrm{w}}\right]$ ). PRED: sentence predictability HP: high-predictability target word; LP: low-predictability target word. Foils: column (1) phonetically similar, (2) semantically plausible, (3) mixed-category-moderately phonetically similar and semantically plausible. The concept of semantic plausibility for foils was clearer for the high- than low-predictability sentences as the latter had been constructed to ensure that any one of a large number of words could reasonably have been used as the final word.

\begin{tabular}{|c|c|c|c|c|c|c|}
\hline \multirow[b]{2}{*}{ ID } & \multirow[b]{2}{*}{ PRED. } & \multirow[b]{2}{*}{ Sentence precursor } & \multirow[b]{2}{*}{ Target word } & \multicolumn{3}{|c|}{ Foils } \\
\hline & & & & 1 & 2 & 3 \\
\hline$P 1$ & & 8-year-old Jane skips every & day & May & time & way \\
\hline$P 2$ & & The musicians went to the pub after the & rehearsal & reversal & performance & dispersa \\
\hline$P 3$ & & Boys like to read books about & cars & bars & sports & sharks \\
\hline$P 4$ & & She had an accident with her & bike & pike & car & kite \\
\hline \multirow[t]{2}{*}{$Q 1$} & $\mathrm{HP}$ & I'll have my ice cream in a & cone & phone & dish & home \\
\hline & LP & Lyle wants to place it in a & & & & \\
\hline \multirow[t]{2}{*}{$Q 2$} & $\mathrm{HP}$ & Avoid the sun by sitting in the & shade & shape & pool & shed \\
\hline & LP & Annoy her mum by spitting in the & & & & \\
\hline \multirow[t]{2}{*}{$Q 3$} & HP & At Ascot many women wear a & hat & cat & shawl & mack \\
\hline & LP & Our mascot read the joke about a & & & & \\
\hline \multirow[t]{2}{*}{$Q 4$} & $\mathrm{HP}$ & The cat chases the & mice & rice & bird & bikes \\
\hline & LP & The chip traces the & & & & \\
\hline \multirow[t]{2}{*}{$N 1$} & $\mathrm{HP}$ & They borrowed money to pay the school & fees & thieves & loan & meals \\
\hline & LP & Deb only offered to get the full & & & & \\
\hline \multirow[t]{2}{*}{$N 2$} & HP & The birds flew overhead in a huge & flock & frock & crowd & block \\
\hline & LP & The boys knew where to look for a huge & & & & \\
\hline \multirow[t]{2}{*}{$N 3$} & $\mathrm{HP}$ & The tourists were shown around by the & guide & bride & kid & guys \\
\hline & LP & The tulips were shoved around by the & & & & \\
\hline \multirow[t]{2}{*}{$N 4$} & $\mathrm{HP}$ & Carl hid his bald head by wearing a & wig & wick & veil & cap \\
\hline & LP & Carl helped the bad men by tearing a & & & & \\
\hline \multirow[t]{2}{*}{ N5 } & $\mathrm{HP}$ & The poor bird's broken its & wing & ring & leg & $\operatorname{limb}$ \\
\hline & LP & I'm sure Lynn spoke of its & & & & \\
\hline \multirow[t]{2}{*}{ N6 } & $\mathrm{HP}$ & I take good close-ups with the & zoom & tomb & lens & boom \\
\hline & LP & I told Rob Clark I'd use the & & & & \\
\hline
\end{tabular}

Listeners used a hand-held electronic voting device to indicate which word they thought they had heard. These devices took the form of small, flat remote controls which fitted into the palm of the hand (Turning Technologies ${ }^{\circledR}$, Youngstown, $\mathrm{OH})$. Responses made using the devices were recorded by a nearby laptop using Turning Technologies software; it was not possible to record reaction times. The order in which foil types were listed on the screen was systematically varied both within and across concerts.

\section{Order of presentation of items within one concert}

All tests began with the same four practice sentences, $P 1-P 4$. The first practice sentence was always sung in quiet; each of the other three sentences was always combined with the same one of the three masker noises (one with babble, one with vowels, and one with $\left.\left[\int^{\mathrm{w}}\right]\right)$. These four practice stimuli were heard always in the same order, shown in Table I. Following seamlessly after this, two HP and two LP sentences, one member of each of four test pairs, were sung in quiet (designated $Q 1-Q 4$ in Table I). Then 12 further sentences were sung in masker noise (both sentences of the 6 remaining test pairs, $N 1-N 6$ ). These 12 comprised $6 \mathrm{HP}$ and $6 \mathrm{LP}$ sentences, with $1 \mathrm{HP}$ and $1 \mathrm{LP}$ sentence (not from the same pair) presented in each combination of masker type and SNR.

\section{Counterbalancing across the six concerts}

In quiet, each member of pairs $Q 1-Q 4$ was sung three times across the six concerts. In noise, each member of pairs $N 1-N 6$ was sung with each noise type and SNR in such a way that a 2 predictability $\times 3$ noise type $\times 2$ SNR design was fully crossed over all 6 concerts, with every member of every pair $N 1-N 6$ heard once in every masker condition. Separation of test sentences sung in quiet $(Q)$ and noise $(N)$ in the design was purely practical, to allow full counterbalancing across the 6 concerts with a realistic limit of 20 trials per concert. The main reason for including the quiet condition was to validate intelligibility and consistency of production across concerts, whose venues varied widely in setup, architectural design, and acoustic environment. Nevertheless, good comparability was expected across concerts since The Clerks, as professionals, have fine control over their performances. For instance, although they were subject to Lombard effects-altered vocalisation, most noticeably loudness, in the presence of masker noise (Lombard, 1911) - in the initial practice sessions, they controlled it well when it was drawn to their attention.

\section{Musical style and setting}

The music for Tales from Babel was in a modern classical style and sung unaccompanied throughout. In the test section, each sentence was set to a discrete musical phrase 
(i.e., the music was not continuous or connected between sentences). The singers paused between each sentence to allow for responses. This pause varied in length, but was usually around $10 \mathrm{~s}$. No lyrics except the test items were presented during the testing phase, although there are lyrics during the other, non-test sections of Tales from Babel. The test section was presented as a "hallucination" by one of the characters, so that the audience should expect strange phrases with no particular link between them. Tales from Babel was normally performed immediately before the interval of each concert, and was preceded by polytextual music to demonstrate situations in which text intelligibility can be problematic. The entire concert lasted around $2 \mathrm{~h}$ and included Renaissance motets and other contemporary choir works in addition to Tales from Babel.

\section{Sentence construction}

Sentence structure was loosely modelled on the R-SPIN sentences (Bilger et al., 1984), in that the last word, the target, was identical in each pair, its predictability being varied by the words preceding it (the precursor). The sentence pairs differed from the R-SPIN set in that they were phonetically controlled and target words were chosen so that observed differences in their intelligibility would largely reflect their predictability from the precursor. The precursors were unique, natural, and meaningful. Sentence pairs had identical numbers of syllables (range 6-10), and identical or almostidentical prosodic structure. Target words were monosyllabic with a neighbourhood density of three or more, and each one's immediate phonetic context was identical in both sentences (with one exception). Each sentence pair was set to a unique melody by Christopher Fox. Melodies ranged between two and six semitones, without large pitch jumps. The pitches of all experimental sentences (pairs N1-N6) fell within the range $F 3$ to $C \# 4(175-277 \mathrm{~Hz})$.

\section{Masker noise types}

Masker sounds emulated the masker sounds typically used in speech studies. The spoken babble was the most similar to sounds used in speech intelligibility-in-noise tasks (Bilger et al., 1984; Wilson et al., 2012). The five background singers read different excerpts simultaneously from Cherry's paper on the cocktail-party phenomenon (Cherry, 1953) at a rapid but constant pace and loudness. This was expected to provide considerable energetic and some informational masking. Vowel sounds were [a], [e], [i], [o], [u], sung in different combinations. In each case, the background vowels were sung on pitches that the target voice used. Thus both the melody and its background harmonization were constant for each sentence pair. Each background singer held the same pitch throughout a test sentence. Pitch ranges between singers were close and dissonant, ranging from 2 to 4 separate pitches (mode of 3 pitches), which formed one or more of the following: major 2nd, minor 3rd, major 3rd, and a tetrachord spanning a tritone. Each singer changed vowel quality at least once during the course of a single sentence. Vowel quality shifts were staggered across singers, so no two singers changed at the same time. Figure 1 shows an example of two vowel masker trials, which happened to be adjacent in this particular randomisation. This shifting vowel background broadly represented speech-modulated noise (SMN) (Brungart, 2001). SMN is usually generated as aperiodic energy shaped with the smoothed amplitude envelope of the long-term average spectrum (LTAS) of the speech. In contrast, the sung vowel spectral envelope had broadly tuned spectral prominences due to the five voices singing close, steady pitches simultaneously, and was amplitude modulated by virtue of intrinsic amplitude modulation characteristic of sung vowels. (See Sec. IIIF for more information.) This manipulation was expected to provide mostly energetic masking in frequency regions below $2 \mathrm{kHz}$. The $\left[\int^{\mathrm{w}}\right]$ masker, produced as standard English "sh", which is liprounded, roughly emulated aperiodic masker noise often used for speech intelligibility-in-noise tests, albeit with a different spectral shape, namely, most energy in the $2-4 \mathrm{kHz}$ region. $\left[\int^{\mathrm{w}}\right]$ onsets were accented by different singers at different times. [ $\left.\int^{\mathrm{w}}\right]$ was expected to be the least effective masker because most of its energy is above $2 \mathrm{kHz}$; [ $\left.\int^{\mathrm{w}}\right]$ will thus be a poor masker of the energy below $2 \mathrm{kHz}$, a frequency region which carries much information relevant to word intelligibility and, when phonated (periodic), is typically higher in amplitude than $\left[\int^{\mathrm{w}}\right]$ at the same frequency.

\section{SNR}

All three types of masker noise were produced loudly and softly, i.e., at relatively higher and lower intensities leading to relatively lower and higher SNRs, respectively, written in the score as $f$ (forte, i.e., loud) and $p$ (piano, i.e., soft) for vowels, $f p$ (loud onset then immediately soft) and $p p$ ( $p i$ anissimo, i.e., very quiet) for $\left[\int^{\mathrm{w}}\right]$, and "loudly and quickly" or "muttered" for babble. Singers kept these levels as consistent as possible across concert performances, following feedback given during each rehearsal by one or more of the authors. An audio example of four sentences sung in the presence of each masker type (quiet, [ $\left.\int^{\mathrm{w}}\right]$, vowels, babble) is provided in the supplementary material. ${ }^{1}$ Figure 2 shows a magnification of some periods from similar-sounding phones from these sentences, to illustrate the acoustic changes to the waveform caused by the masker sound. The maskers $\left[\int^{\mathrm{w}}\right]$ and babble result in a less clearly periodic target signal.

\section{B. Procedure}

Participants were seated side-by-side in rows as in a normal concert performance. It would have been possible for participants to see each other's responses, but they would have had to do so deliberately and there was no evidence of such collusion.

After the functioning of the voting device and associated interactive displays had been explained, participants were familiarised with the device early in the concert by using it to answer questions about their age, LS (i.e., whether or not English was their first language), musical training (measured by years of formal music lessons), vision, and hearing. The concert then continued. Singers obscured their mouths behind their scores. No feedback was given during the test, 


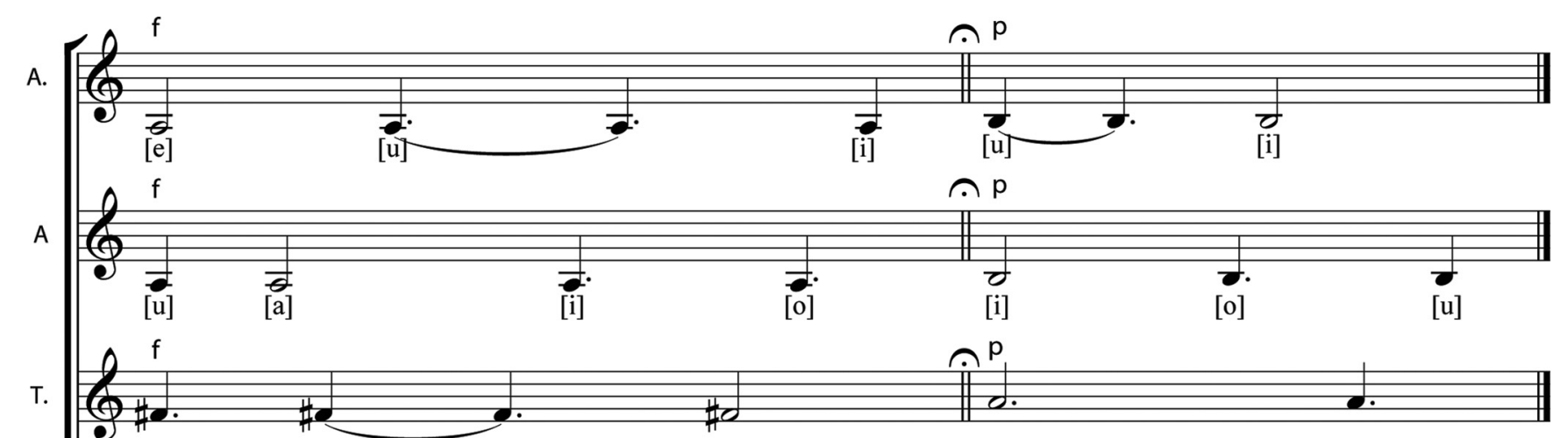

[a]

[o]

[e]

[u]

[e]

[o]
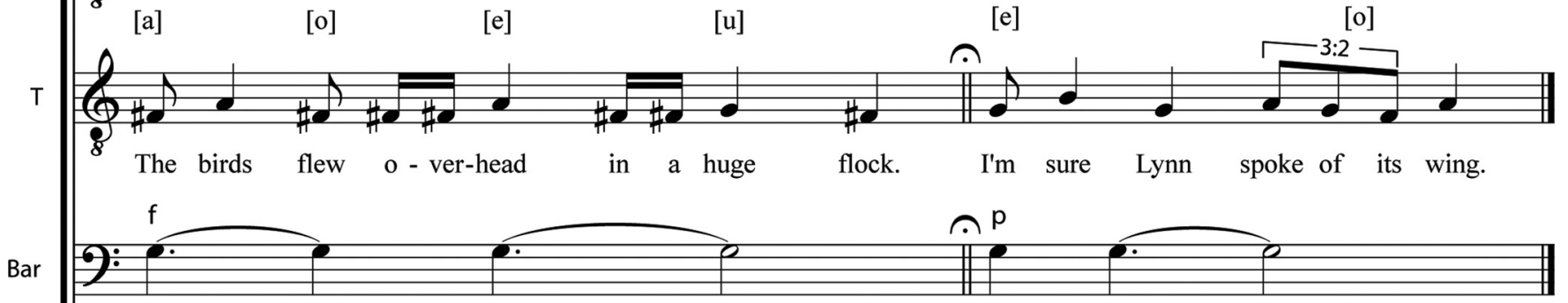

[a]

[o]

[e]

[u]

[u]

[a]

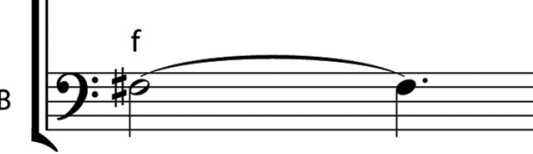

[e]

[u]

[a]

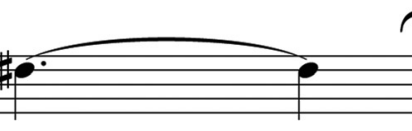

[i]

[a]

[o]

FIG. 1. Excerpt of the score composed by C. Fox showing two vowel masker trials adjacent to each other. The first trial is to be performed with the relatively low SNR (high noise level), the second with a high SNR. The fermata that separates the two trials (the symbol over the double bar-lines following the word flock) indicates a grand pause, allowing audience members to give a response to the previous trial.

but, if time allowed, a short summary of results was given at the end of the experiment.

\section{Participants and recruitment}

Participants were 354 volunteers. Those who reported hearing or vision problems were excluded $(n=28)$. A further seven participants were excluded for technical reasons. The final analysis therefore included 319 participants. Table II gives venue and singer information, as well as audience numbers for native and non-native English listeners for each concert. Figure 3 shows the distribution of ages of audience members for each concert.

Participants were recruited through concert advertisements produced by both the host institutions and The Clerks. The concerts were described as exploring the cocktail party problem, and it was made clear that there would be an interactive element as well as musical performances. The demographic makeup of audiences varied and included students, academics, and retirees. There was no coercion to participate,
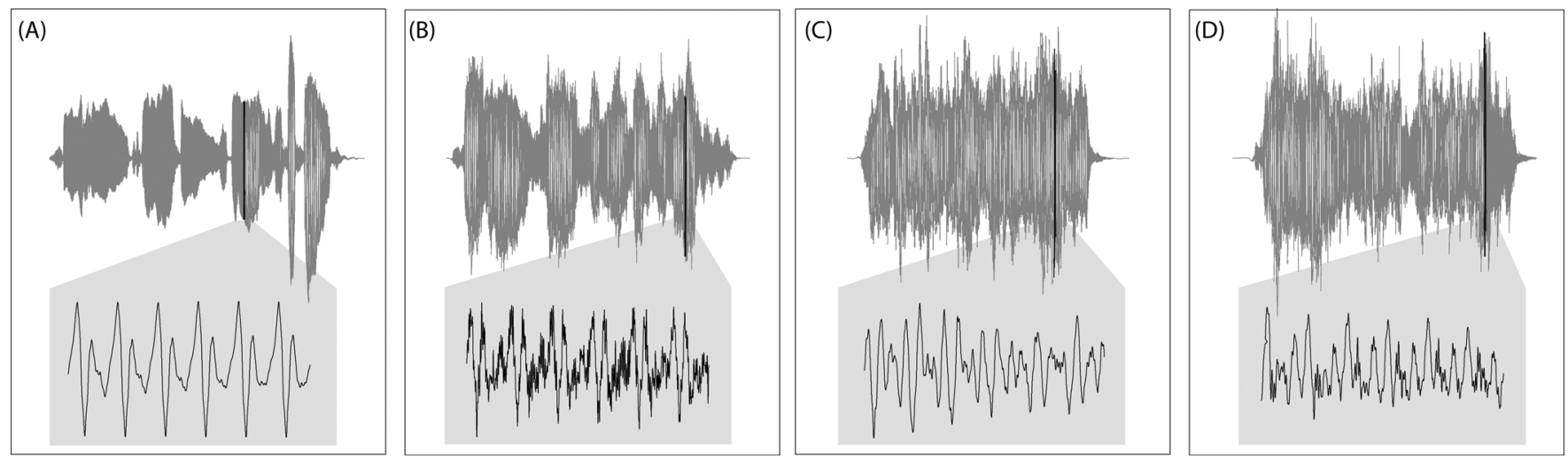

FIG. 2. Waveforms of four sentences, each sung in one of the four masker conditions: A (in quiet): "She hit the baseball with the bat"; B ([against $\left.\int^{\mathrm{w}}\right]$ ): "They hoped that they'd soon find the lock"; C (against vowels): "Another word for pig is hog"; D (against babble): "The door key was still in the lock." The lower panel displays six periods of the underlined phone [D] for lock and hog, and [o] for ball, with their respective maskers, taken from the region indicated by the dark vertical line on the complete waveform (see footnote 1). 
TABLE II. Venue, background singer ID, audience size, and number of native English listeners ( $L 1)$ vs non-native listeners (Not $L 1)$ for all six concerts. The target-sentence tenor was the same in each concert. A total of three alto (A), two tenor (T), one baritone (BA), and three bass (B) singers comprised the pool of voices from which the five background singers were drawn. Continuity between concerts was good: one alto (A1) and the baritone sang in all six concerts, A 2 sang in five, and $\mathrm{T} 2$ and B2 sang in four concerts.

\begin{tabular}{|c|c|c|c|c|c|c|}
\hline \multirow[b]{2}{*}{ Concert } & \multirow[b]{2}{*}{ Location } & \multirow[b]{2}{*}{ Venue description } & \multirow[b]{2}{*}{ Background singer ID } & \multicolumn{3}{|c|}{ Status of English } \\
\hline & & & & $L 1$ & Not $L 1$ & Unknown \\
\hline 1 & Cambridge & 500-seat rectangular concert hall & $\mathrm{A} 1, \mathrm{~A} 3, \mathrm{~T} 1, \mathrm{BA}, \mathrm{B} 1$ & 14 & 11 & 2 \\
\hline 2 & York & 350-seat hexagonal concert hall & $\mathrm{A} 1, \mathrm{~A} 2, \mathrm{~T} 2, \mathrm{BA}, \mathrm{B} 2$ & 48 & 19 & 20 \\
\hline 3 & Birmingham & 150 -seat rectangular recital hall & $\mathrm{A} 1, \mathrm{~A} 2, \mathrm{~T} 2, \mathrm{BA}, \mathrm{B} 3$ & 13 & 7 & 12 \\
\hline 4 & London & 400-seat rectangular concert hall & $\mathrm{A} 1, \mathrm{~A} 2, \mathrm{~T} 1, \mathrm{BA}, \mathrm{B} 2$ & 23 & 4 & 1 \\
\hline 5 & Durham & 250-seat multi-purpose hall & $\mathrm{A} 1, \mathrm{~A} 2, \mathrm{~T} 2, \mathrm{BA}, \mathrm{B} 2$ & 20 & 15 & 21 \\
\hline 6 & Glasgow & 150 -seat rectangular concert hall & $\mathrm{A} 1, \mathrm{~A} 2, \mathrm{~T} 2, \mathrm{BA}, \mathrm{B} 2$ & 65 & 11 & 13 \\
\hline
\end{tabular}

and almost all audience members did participate unless they felt there was a good reason not to (e.g., hearing or vision problems).

\section{RESULTS}

\section{A. Statistical models}

Responses were coded as 1 for correct and 0 for incorrect. The data were subjected to two mixed-effects logistic regressions using IBM SPSS Statistics 21. Model 1 included all noise types plus the quiet background condition, but not SNR, since SNR could not be manipulated in the quiet condition. Model 2 included SNR as a variable, but not the quiet background condition. Concert and Participants were included as random intercepts. Predictability, Noise Type, Age, LS, and Musical Training were fixed factors in both models; Model 2 also had SNR as a fixed factor. Overall intelligibility was $77 \%$ for Model 1 and $72 \%$ for Model 2 .

Initially each model was run with all main effects and two-way interactions, this being the most powerful model the data allowed us to run. In both of these initial analyses, Musical Training was not significant either as a main effect or as part of an interaction, justifying the removal of Musical Training as part of any interaction in the subsequent model building (shown in the supplementary material ${ }^{1}$ ). All subsequent models used stepwise forward regression, where in a first step, all factors were included as main effects; two-way interactions were added as a second step; and three-way interactions were added as a third step. Non-significant factors were removed at each step. Musical Training was

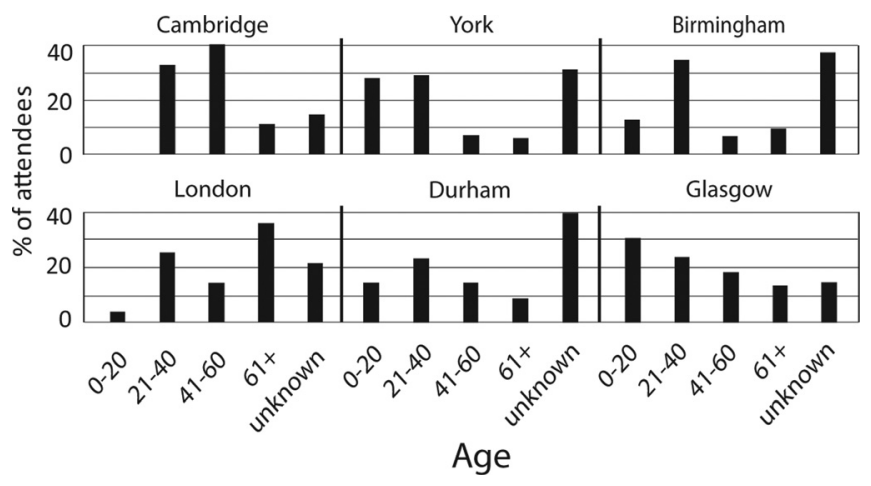

FIG. 3. Distribution of age groups across concerts. omitted from these models after the first step since it was not significant as a main effect and had been shown by the initial models not to contribute to any significant interactions. Model 1 correctly classified $79 \%$ of responses and Model 2 correctly classified $78 \%$ of responses.

Not all participants responded to every trial, and some also failed to complete the questionnaire regarding age and native language. It was suspected that these data were not missing completely at random: for example, those struggling with the task may have been more likely to fail to respond altogether during experimental trials than those finding the task easier. Furthermore, the proportion of participants who failed to respond to at least one demographic question was fairly large (see "unknown" category in Table II and demographic information in Fig. 3). For these reasons, a simple listwise deletion of non-respondents was not considered appropriate. Instead, data from all participants were included in the analysis, and non-responses were coded as an additional category. This means that reported results include data from all participants, but results regarding age or native language refer only to comparisons involving those groups of participants whose age and/or LS was known (e.g., known native versus known non-native speakers).

\section{B. Intelligibility in quiet}

The data confirm that sung words can be highly intelligible in meaningful sentences, even when the critical word is unpredictable from context. Model 1 (Tables III and IV, and Fig. 4) shows that, in the quiet condition, intelligibility was high overall but highly-predictable words were nonetheless more intelligible than less-predictable ones $[96.4 \%$ vs $91.0 \%, t(5076)=3.979, p<0.001]$. A slight decrease in

TABLE III. Statistical results for Model 1 parameters that achieved significance. Dependent variable was correct target word identification.

\begin{tabular}{lrrc}
\hline \hline Independent variable & \multicolumn{1}{c}{ F } & df & Sig. \\
\hline Predictability & 51.31 & 1 & $<0.001$ \\
Noise Type & 135.29 & 3 & $<0.001$ \\
Age & 9.09 & 4 & $<0.001$ \\
LS & 7.83 & 2 & $<0.001$ \\
Noise Type * Predictability & 5.69 & 3 & $<0.005$ \\
Noise Type * Age & 2.36 & 12 & $<0.01$ \\
Predictability * LS & 6.37 & 2 & $<0.005$ \\
\hline \hline
\end{tabular}


TABLE IV. Estimated means, standard error (SE), and confidence intervals (CIs) for all levels of significant main effects of Model 1. Results are given as estimates on a linear scale, and correspond to the results as shown in Fig. 4.

\begin{tabular}{|c|c|c|c|c|c|}
\hline \multirow[b]{3}{*}{ Independent variable } & \multirow[b]{3}{*}{ Level } & \multicolumn{4}{|c|}{ Linear estimates } \\
\hline & & \multirow[b]{2}{*}{ Mean } & \multirow[b]{2}{*}{$S E$} & \multicolumn{2}{|c|}{$95 \% C I$} \\
\hline & & & & Lower & Upper \\
\hline \multirow[t]{4}{*}{ Noise Type } & Babble & 0.64 & 0.05 & 0.54 & 0.73 \\
\hline & Vowel & 0.69 & 0.05 & 0.60 & 0.78 \\
\hline & {$\left[\int^{w}\right]$} & 0.90 & 0.02 & 0.85 & 0.93 \\
\hline & Quiet & 0.94 & 0.01 & 0.91 & 0.96 \\
\hline \multirow[t]{2}{*}{ Predictability } & High & 0.87 & 0.02 & 0.82 & 0.91 \\
\hline & Low & 0.78 & 0.04 & 0.70 & 0.84 \\
\hline \multirow[t]{5}{*}{ Age } & $0-20$ & 0.87 & 0.03 & 0.80 & 0.91 \\
\hline & $21-40$ & 0.88 & 0.03 & 0.82 & 0.92 \\
\hline & $41-60$ & 0.83 & 0.04 & 0.75 & 0.89 \\
\hline & $60+$ & 0.75 & 0.05 & 0.65 & 0.83 \\
\hline & Unknown & 0.80 & 0.04 & 0.71 & 0.86 \\
\hline \multirow[t]{3}{*}{ LS } & L1 not English & 0.78 & 0.04 & 0.69 & 0.84 \\
\hline & L1 English & 0.84 & 0.03 & 0.77 & 0.89 \\
\hline & Unknown & 0.87 & 0.03 & 0.79 & 0.92 \\
\hline
\end{tabular}

intelligibility of sentences in quiet for the oldest group was not significant (0-20: 94.9\%, 21-40: 96.4\%, 41-60: 94.3\%, $60+: 91.0 \%, p>0.05)$.

\section{Intelligibility in noise}

Tables V and VI and Fig. 5 show Model 2 results, which include SNR. Main effects are discussed first. They were as predicted from the speech literature, although it should be borne in mind that each interacted significantly with other factors. In both models, listeners were more accurate for high-predictability than low-predictability words and in high than low SNRs. Comparing across all noise type conditions, words sung in a quiet background resulted in the highest intelligibility followed by words sung in the [ $\left.\int^{\mathrm{w}}\right]$ masker, then the vowel masker, and then the babble masker. All pairwise comparisons between noise types were significant in both models $[p<0.05$, sequentially Bonferroni-corrected throughout (Holm, 1979)]. The age main effect showed older listeners performing less well than younger listeners. A general decline was apparent from the age of 40, and pairwise comparisons revealed that those aged over 60 performed significantly worse than all other age groups in both models (all
TABLE V. Statistical results for Model 2 parameters that achieved significance. Dependent variable was correct target word identification.

\begin{tabular}{lrcc}
\hline \hline Independent variable & F & df & Sig. \\
\hline Predictability & 41.86 & 1 & $<0.001$ \\
SNR & 149.30 & 1 & $<0.001$ \\
Noise Type & 89.95 & 2 & $<0.001$ \\
Age & 9.20 & 4 & $<0.001$ \\
LS & 6.81 & 2 & $<0.005$ \\
Noise Type * Predictability & 6.40 & 2 & $<0.005$ \\
Noise Type * SNR & 23.63 & 2 & $<0.001$ \\
Noise Type * Age & 3.66 & 8 & $<0.001$ \\
Predictability * LS & 5.29 & 2 & $<0.01$ \\
\hline \hline
\end{tabular}

$p<0.05)$. Native English listeners performed better than non-native listeners $(p<0.005)$.

However, as noted, the influence of experimental factors was often not independent and Noise Type in particular had a strong modifying effect. Figures 4 [with noise level (SNR) excluded] and 5 (with quiet excluded) show essentially the same results, so $p$ values are only reported separately for both models when they differ. Both models show that while the intelligibility advantage of high-predictability over lowpredictability words was highly significant for the $\left[\int^{\mathrm{w}}\right]$ and spoken babble maskers $(p<0.001)$, it was not significant for the vowel masker $(p>0.1)$. In addition, the vowel and babble masker conditions were different from each other in the lowpredictability condition (higher intelligibility in vowels than in babble, hereafter coded vowel $>$ babble, $p<0.005)$, but not in the high-predictability condition ( $p>0.1)$ [Figs. 4(A) and 5(A)]. Noise Type also interacted with SNR [Fig. 5(B)] in that vowel and babble conditions were significantly different from each other in the low SNR condition (vowel $>$ babble, $p<0.001)$, but not in the high SNR condition $(p>0.5)$. The type of masker noise affected the age groups differently, with listeners over 40 yrs old performing disproportionately poorly in the vowel condition: in both models, pairwise comparisons showed that listeners in the 41-60 and 60+ age groups performed no better in the vowel condition than in babble (all $p>0.05$ ), and both groups performed significantly worse than all other age groups in the vowel condition (all $p<0.05)$ [Figs. 4(B) and 5(C)]. Finally, in addition to an overall intelligibility benefit for native listeners $(p<0.005$ in both models), there was also an interaction with Predictability $(p<0.005$ in Model 1 and $p<0.01$ in Model $2)$, confirming that native listeners benefitted more from
(A) Noise Type $x$ Predictability

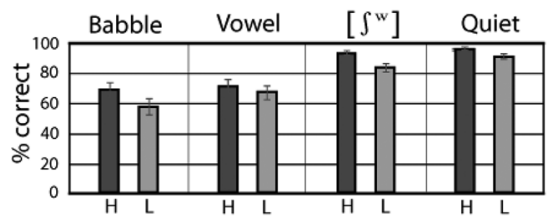

Predictability
(B) Noise Type $x$ Age

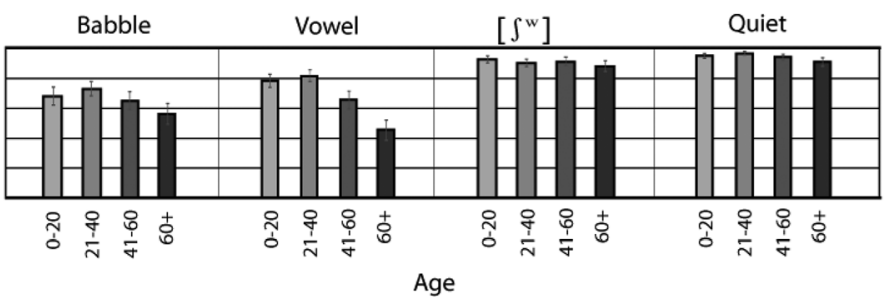

(C) Language $x$ Predictability

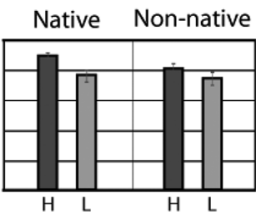

Predictability

FIG. 4. Mean percent correct word identification (and SE) as estimated by Model 1 for the interactions of Noise Type (including quiet) with (A) Predictability and (B) Age, and (C) LS with Predictability. See Table III for details of model parameters and Table IV for details of results. 
TABLE VI. Estimated means, SE, and CIs for all levels of significant main effects of Model 2. Results are given as estimates on a linear scale, and correspond to the results as shown in Fig. 5.

\begin{tabular}{|c|c|c|c|c|c|}
\hline \multirow[b]{3}{*}{ Independent variable } & \multirow[b]{3}{*}{ Level } & \multicolumn{4}{|c|}{ Linear estimates } \\
\hline & & \multirow[b]{2}{*}{ Mean } & \multirow[b]{2}{*}{$S E$} & \multicolumn{2}{|c|}{$95 \% C I$} \\
\hline & & & & Lower & Upper \\
\hline \multirow[t]{3}{*}{ Noise Type } & {$\left[\int^{\mathrm{w}}\right]$} & 0.90 & 0.02 & 0.84 & 0.93 \\
\hline & Vowel & 0.70 & 0.05 & 0.60 & 0.79 \\
\hline & Babble & 0.65 & 0.05 & 0.54 & 0.74 \\
\hline \multirow[t]{2}{*}{ SNR } & Low & 0.66 & 0.05 & 0.56 & 0.76 \\
\hline & High & 0.85 & 0.03 & 0.78 & 0.90 \\
\hline \multirow[t]{2}{*}{ Predictability } & High & 0.82 & 0.04 & 0.74 & 0.88 \\
\hline & Low & 0.71 & 0.05 & 0.61 & 0.79 \\
\hline \multirow[t]{5}{*}{ Age } & $0-20$ & 0.82 & 0.04 & 0.74 & 0.89 \\
\hline & $21-40$ & 0.84 & 0.04 & 0.76 & 0.89 \\
\hline & $41-60$ & 0.77 & 0.05 & 0.66 & 0.85 \\
\hline & $60+$ & 0.66 & 0.06 & 0.53 & 0.77 \\
\hline & Unknown & 0.73 & 0.05 & 0.62 & 0.82 \\
\hline \multirow[t]{3}{*}{ LS } & L1 not English & 0.70 & 0.05 & 0.59 & 0.79 \\
\hline & L1 English & 0.78 & 0.04 & 0.70 & 0.85 \\
\hline & Unknown & 0.81 & 0.05 & 0.70 & 0.89 \\
\hline
\end{tabular}

highly-predictable words than non-native listeners. In fact, post hoc testing showed that while the intelligibility difference for HP/LP sentences was highly significant for native listeners in both models $(p<0.001)$, it was less so $(p<0.05$, Model 1) or not at all ( $p>0.05$, Model 2) for non-native listeners [see also Figs. 4(C) and 5(D)].

\section{Stability across concerts}

As the stability of relative effects across concerts was of interest, Fig. 6 shows results for each concert. Absolute levels of intelligibility varied, but the pattern of effects was largely consistent across concerts, although some differences occurred. To assess the significance of these differences, Concert was re-coded as a fixed factor in a fixed-effects logistic regression (Model 3). The other fixed factors in Model 3 were the same as those in Model 2. Tables VII and VIII show the results.

The main effect of Concert was significant $(p<0.001)$, confirming that overall intelligibility differed between the six concerts. Only two other variables, Noise Type $(p<0.05)$ and SNR $(p<0.001)$, interacted with Concert;
(A) Noise Type $x$ SNR $x$ Concert
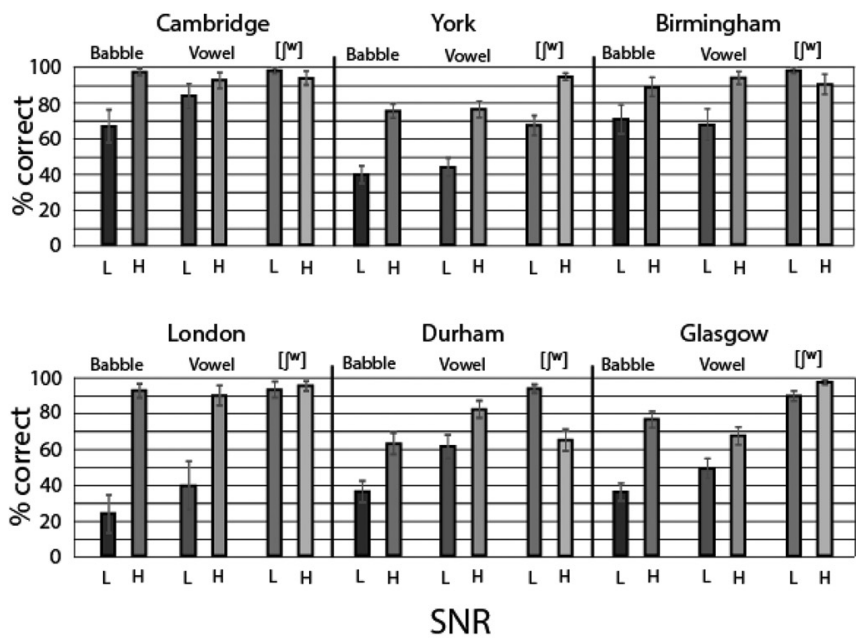

(B) Noise Type $x$ Predictability $x$ Concert
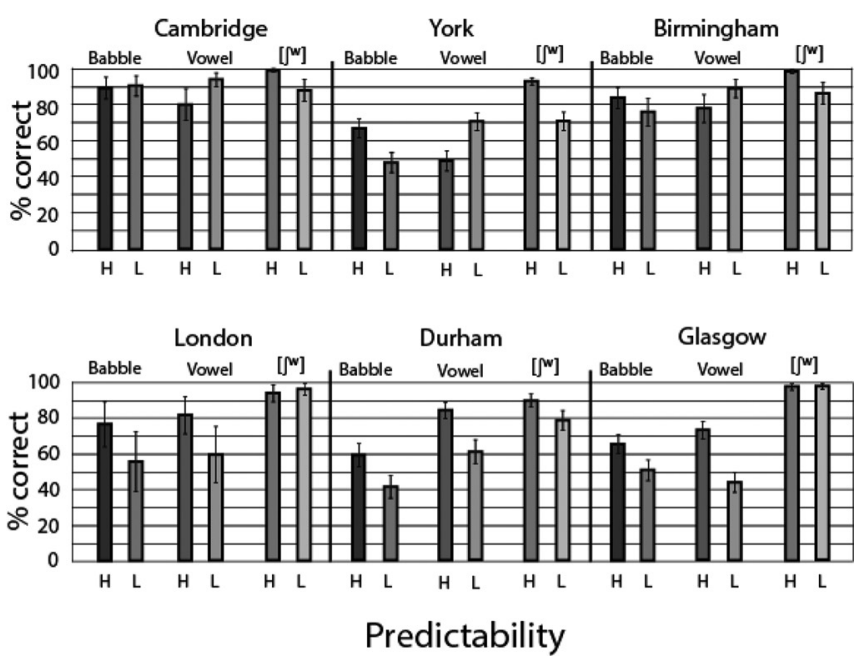

FIG. 6. Mean percent correct word identification (and SE) as estimated by Model 3 for the interactions of concert with (A) Noise Type and SNR and (B) Noise Type and Predictability. H: high SNR (A) or Predictability (B). L: low SNR (A) or Predictability (B). See Table VII for model parameters and their significance levels, and Table VIII for details of results.

Predictability, Age, and LS did not. The interaction with Noise Type occurred because intelligibility was uniformly high in all concerts for the $\left[\int^{\mathrm{w}}\right]$ masker but decreased by different amounts for the babble and vowel masker in different concerts: in York, London, Durham, and Glasgow
(A) Noise Type $x$ Predictability

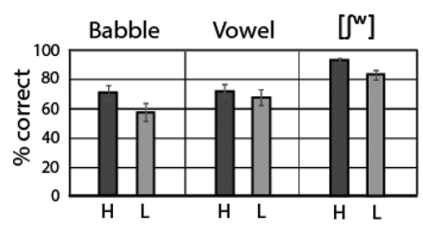

Predictability
(B) Noise Type $x$ SNR

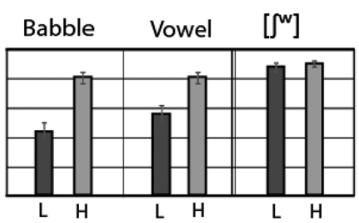

SNR
(C) Noise Type $x$ Age

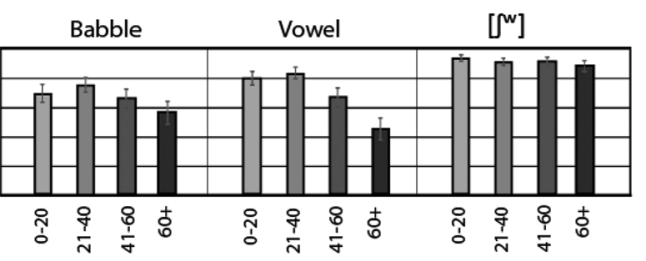

Age
(D) Language $\mathrm{x}$ Predictability

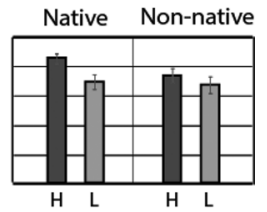

Predictability

FIG. 5. Mean percent correct word identification (and SE) as estimated by Model 2 for the interactions of Noise Type (excluding quiet) with (A) Predictability, (B) SNR, (C) Age, and (D) LS with Predictability. H: HP or SNR. L: LP or SNR. See Table V for model parameters and their significance levels, and Table VI for details of results. 
TABLE VII. Statistical results for Model 3 parameters that achieved significance. Dependent variable was correct target word identification.

\begin{tabular}{lccc}
\hline \hline Independent variable & F & df & Sig. Value \\
\hline Concert & 6.90 & 5 & $<0.001$ \\
Concert * Noise Type & 2.32 & 10 & $<0.05$ \\
Concert * SNR & 9.20 & 5 & $<0.001$ \\
Concert * Noise Type * Predictability & 5.06 & 10 & $<0.001$ \\
Concert * Noise Type * SNR & 5.63 & 10 & $<0.001$ \\
\hline \hline
\end{tabular}

intelligibility was higher for the $\left[\int^{\mathrm{w}}\right]$ masker than for vowel and babble masker (all $p<0.05$ ); in Cambridge intelligibility did not differ between the $\left[\int^{\mathrm{w}}\right]$ masker and either the vowel or babble masker (both $p>0.1$ ); and in Birmingham intelligibility differed only between the $\left[\int^{\mathrm{w}}\right]$ and babble masker $(p<0.05)$, being better for the $\left[\int^{\mathrm{w}}\right]$ condition. The interaction between Concert and SNR indicated that in York, London, and Glasgow, intelligibility was lower in low SNRs than in high SNRs (all $p<0.001$ ) whereas in Cambridge, Birmingham, and Durham SNR did not affect intelligibility (all $p>0.05$ ).

Two three-way interactions involving Concert were also significant. Concert interacted with Noise Type and SNR largely because the difference between high and low SNRs was not stable for the $\left[\int^{\mathrm{w}}\right]$ masker [Fig. 6(A)]. The typical pattern of lower accuracy in low SNRs was true for the [ $\left.\int^{\mathrm{w}}\right]$ masker in only two concerts (York, Glasgow, $p<0.05$ ). The direction of difference was reversed for Durham $(p<0.001)$, while Birmingham, Cambridge, and London showed no change $(p>0.1)$. Moreover, Concert interacted with Noise Type and Predictability due to inconsistencies within both the vowel and $\left[\int^{\mathrm{w}}\right]$ masker. Against the vowel masker, highly-predictable words were only significantly more accurate than low ones in Durham and Glasgow $(p<0.005)$. There was no difference in Cambridge, Birmingham, and London (all $p>0.1$ ), and York reversed the difference $(p<0.005)$. Against the $\left[\int^{\mathrm{w}}\right]$ masker, high-predictability words were only identified better in Durham, York, and Birmingham $(p<0.05)$ [Fig. 6(B)].

\section{E. Incorrect responses}

The pattern of erroneous choices amongst the three types of foil (Table I) shows that listeners always relied most

TABLE VIII. Estimated means, SE, and CIs for all levels of Concert in Model 3. Results are given as estimates on a linear scale, and correspond to the results as shown in Fig. 6 .

\begin{tabular}{lcccccc}
\hline \hline & & \multicolumn{4}{c}{ Linear estimates } \\
\cline { 4 - 7 } & & & & & \multicolumn{2}{c}{$95 \%$ CI } \\
\cline { 4 - 7 } Independent variable & Level & Mean & SE & Lower & Upper \\
\hline \multirow{2}{*}{ Concert } & 1 & Cambridge & 0.93 & 0.03 & 0.85 & 0.97 \\
& 2 & York & 0.70 & 0.03 & 0.64 & 0.75 \\
& 3 & Birmingham & 0.89 & 0.03 & 0.81 & 0.94 \\
& 4 & London & 0.81 & 0.07 & 0.63 & 0.91 \\
& 5 & Durham & 0.71 & 0.04 & 0.63 & 0.77 \\
& 6 & Glasgow & 0.77 & 0.03 & 0.71 & 0.83 \\
\hline \hline
\end{tabular}

on the acoustic signal, and used the semantically-plausible but phonetically-unrelated option only in the most challenging listening conditions. Thus the vast majority of errors overall were phonetic [foil type 1, 53\% of all errors in Model 2 (no quiet)], with mixed-category errors ["moderately phonetically similar and semantically plausible" (foil type 3)] the next most frequent category $(28 \%)$. This general pattern was not observed, however, in three of the six masker noise conditions. In the two most challenging listening conditions, the babble and vowel maskers at low SNRs, although phonetic errors (foil type 1) were by far the most common, semantically-plausible errors outnumbered mixed-category errors, especially for vowels at low SNRs. Errors in babble at low SNRs were: phonetic $=47 \%$; semantic $=28 \%$; mixed $=25 \%$. In vowels at low SNRs, errors were: phonetic $=54 \%$; semantic $=31 \%$; mixed $=15 \%$. Against the $\left[\int^{\mathrm{w}}\right]$ masker at low SNRs, mixed phonetic and semantic word choices outnumbered phonetic choices (57\% vs $43 \%$ ), and there were no semanticallyplausible (foil type 2) errors at all. These patterns indicate that audiences were attending closely to the signal in all masker noise conditions.

\section{F. Acoustic characterization of background noises}

In contrast with common laboratory practice, where background noises are often generated before stimulus presentation and according to rigorous specifications, all noises in the current study were produced live at each concert. As described above in Sec. II A 5, the sounds were chosen because their contrasting spectral compositions were expected to have different masking effects. The singers were given standard speech-sound descriptions and demonstrations of the sounds to make, but within each category of speech sound, spectral composition was not (and could not be) tightly controlled. Background sounds could not be recorded alone during the concerts, because they were coterminous with the target singing. The analyses reported here are thus made from recordings The Clerks made in a professional-quality recording studio. Their spectral envelopes are informative, but their relative amplitudes therefore do not necessarily reflect the relative amplitudes used in a concert. Figure 7 displays superimposed LTAS of a single target sentence and the three masker noise types that accompanied it. They were calculated using Praat's LTAS facility (Boersma and Weenink, 2015) with $400 \mathrm{~Hz}$ bandwidth bins in Fig. 7(A), and $100 \mathrm{~Hz}$ bins in Fig. 7(B), and each is plotted, without pre-emphasis and amplitude-normalised to $65 \mathrm{~dB}$ sound pressure level, on an equivalent rectangular bandwidth (ERB)-rate frequency scale (Moore and Glasberg, 1983). The 400-Hz bin window [Fig. 7(A)] shows relatively smooth envelopes for all four sounds. The sung vowel masker and the target sentence have similar sharp roll-offs above about $1 \mathrm{kHz}$, with evidence of a singers' formant centered just below $3 \mathrm{kHz}$ for the target sentence, and about $500 \mathrm{~Hz}$ higher for the vowel masker. Spoken babble has a rather smoother envelope across all frequency ranges, and the distinctive pattern typical of aperiodic [ $\left.\int^{\mathrm{w}}\right]$ is also clearly evident, with the highest energy in a relatively narrow band above about $2.2 \mathrm{kHz}$. 
(A)
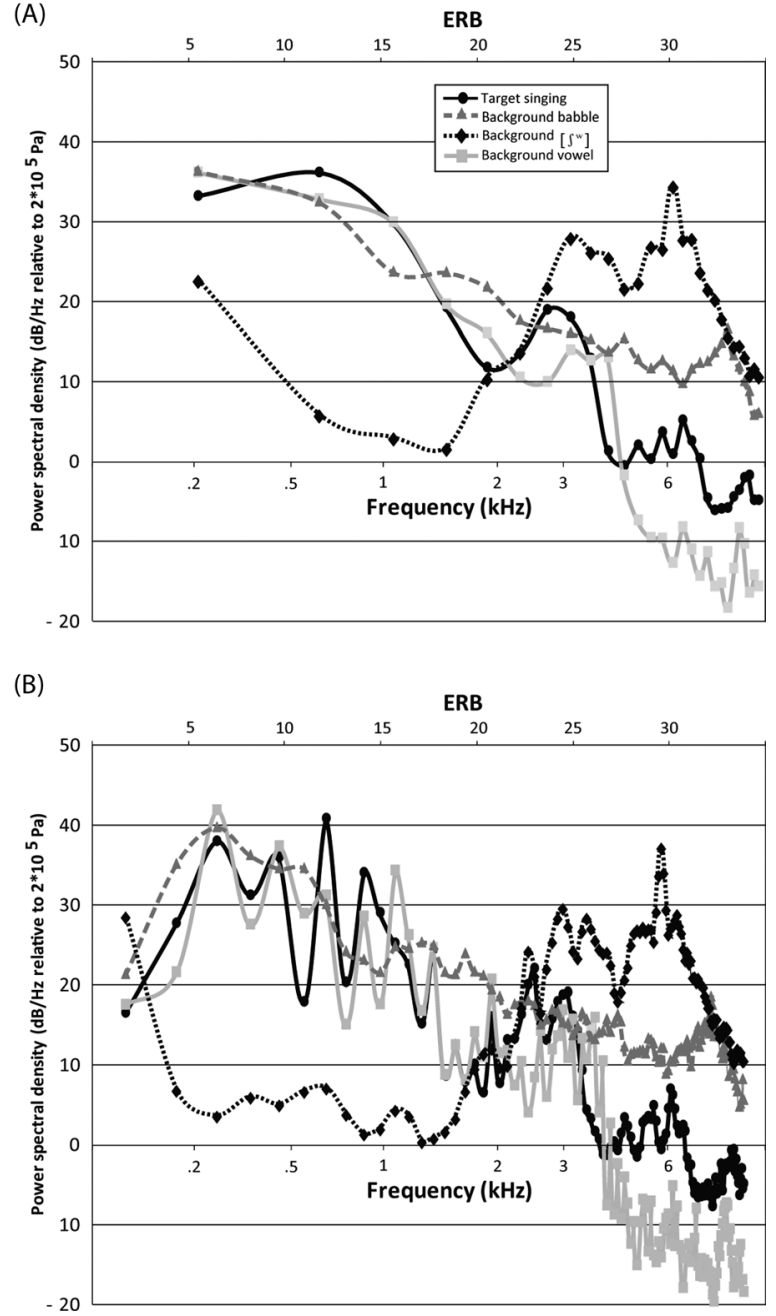

FIG. 7. Normalised long-term average power spectra for one sung sentence ("Another word for pig is hog"), and the matching vowel, babble and [ $\left.\int^{\mathrm{w}}\right]$ maskers, made from studio recordings of the same singers done for demonstration purposes. LTAS was calculated in Praat using (A) 400-Hz and (B) $100-\mathrm{Hz}$ frequency bins before frequency values were converted to ERBs, which approximate the bandwidth of cochlear filters (Moore and Glasberg, 1983).

The heavily-smoothed spectra of Fig. 7(A), however, may not accurately reflect the patterns of energetic masking experienced by listeners. The 100-Hz bins of Fig. 7(B) probably give a more accurate picture. The envelopes of babble and $\left[{ }^{\mathrm{w}}\right]$ are broadly similar to those in Fig. 7(A), but those for the target sentence and the vowels show marked spectral prominences every $200 \mathrm{~Hz}$ in the ranges $250-850 \mathrm{~Hz}$ (target) and $250-1350 \mathrm{~Hz}$ (vowel masker noise). Since the ERB-rate spectrum reflects cochlear frequency resolution, these peaks may be resolved by the ear. Both the broad-bandwidth babble and the more closely-tuned spectral prominences of the sung vowels should provide significant energetic masking, although the babble might be expected to be more effective since it lacks the significant troughs of the sung vowels.

The difference in masking influence between babble and vowel masker (described in Sec. III C above and Figs. 4 and 5) is presumably mainly due to the fact that the babble, comprising different texts rapidly spoken with the natural pitches of three male and two female speakers, introduced significant and relatively uniform energetic masking across the entire low frequency range, as well as some informational masking. In contrast, the steady pitches of the sung vowels, comprising 2-4 simultaneous pitches spanning 2-6 semitones, introduced very high energetic masking in relatively narrow frequency bands corresponding to the harmonic complexes of the pitches, separated by deep troughs. How these differences in spectral pattern may have affected the efficiency of each noise masker for the target sentences is further discussed in Sec. IV.

\section{G. SNR}

Because speech and noise levels were produced live, we obtained recordings of three concerts and used them to check that the high and low SNRs did indeed differ and to obtain an estimate for the variability of SNRs between concerts. The recordings were made with a hand-held recording device placed on a seat in the front row. Necessarily, because the concerts were live and target and masker signals were produced simultaneously, all measurements were approximate and the presentation level of the noise masker was inferred rather than directly measured. In the quiet condition, the presentation level of the target stimuli (sentences) was directly measured. In the noise masker conditions, the signal level was measured as a combination of target and masker noise, and estimates of masker noise level derived by assuming that the level of the target sentences was constant in quiet and noise, and that all additional energy in the overall signal, compared to quiet, was contributed by the masker noise. The estimates for the level of the noise were derived using the equation

$$
\begin{aligned}
\text { Noise }(\text { in } \mathrm{dB})= & 10 \log _{10}\left(10^{(\text {Overall/10) }}\right. \\
& \left.-10^{(\text {Sentences in silence } / 10)}\right) .
\end{aligned}
$$

Based on the noise level estimate, estimates of SNRs for each condition of each concert and differences in SNR between the high and low SNR conditions were calculated. Table IX provides data for measured ("actual") and estimated ("est.") signal and noise levels for the three concerts: Birmingham (3), London (4), and Glasgow (6).

The results showed some interesting trends. First, the "estimated SNR (dB)" column in Table IX shows that levels of the babble masker were produced most consistently between concerts, low SNRs being within $2.2 \mathrm{~dB}$ and high SNRs within $1.6 \mathrm{~dB}$ of each other (ranges -8.51 to -6.36 for low SNR, and -2.41 to -0.86 for high SNRs). This meant that the changes in SNR between SNR conditions were remarkably similar across all three concerts [within $1 \mathrm{~dB}$, see $\Delta \mathrm{SNR}$ (dB) column]. Second, the variability was greater for the production of the vowel masker, with high estimated SNR levels showing a variation of up to $2.9 \mathrm{~dB}$ and low levels of $6.4 \mathrm{~dB}$ (ranges -11.81 to -8.96 , and -6.51 to -0.16 , respectively). This variability also led to a greater variability of the resulting SNR change, which varied by up to $3.5 \mathrm{~dB}$ between concerts [5.3 to $8.8 \mathrm{~dB}$, see $\Delta$ SNR (dB) column]. Last, the highest variability was seen for the production of the $\left[\int^{\mathrm{w}}\right]$ masker, particularly in the high SNR condition. While the levels in the low SNR condition were within the range of other types of masker both in terms of 
TABLE IX. Sentences in quiet (actual) dB: the sound level of sentences by themselves measured directly in the quiet condition. Overall (actual): the sound level of the noise masker measured in combination with the sentence. Noise (est.): derived by assuming that the level of the target sentences was constant across quiet and noise conditions, and that all additional energy in the overall combined signal was contributed by the masker noise (see text for further explanation). Estimated SNR (dB): derived SNR value for each condition in each concert. $\Delta$ SNR (dB): differences in SNR (high-low) between high and low SNR conditions for each concert. Estimates contributing to each SNR difference are marked by the same alignment: left, middle, and right for concerts 3, 4, and 6, respectively.

\begin{tabular}{|c|c|c|c|c|c|c|c|c|c|}
\hline \multirow[b]{2}{*}{ Noise type } & \multirow[b]{2}{*}{ SNR condition } & \multirow[b]{2}{*}{ Concert } & \multirow{2}{*}{$\begin{array}{l}\text { Sentences in quiet } \\
\quad(\text { actual })(\mathrm{dB})\end{array}$} & \multirow{2}{*}{$\begin{array}{l}\text { Overall } \\
\text { (actual) }\end{array}$} & \multirow[b]{2}{*}{ Noise (est.) } & \multirow{2}{*}{$\begin{array}{l}\text { Estimated } \\
\text { SNR }(\mathrm{dB})\end{array}$} & \multicolumn{3}{|c|}{$\begin{array}{c}\Delta \mathrm{SNR}(\mathrm{dB}) \text { (high-low) } \\
\text { in each concert }\end{array}$} \\
\hline & & & & & & & 3 & 4 & 6 \\
\hline \multirow[t]{6}{*}{ Babble } & Low & 3 & 64.04 & 71.33 & 70.4 & -6.36 & 5.5 & & \\
\hline & & 4 & 55.54 & 63.91 & 63.2 & -7.66 & & 5.7 & \\
\hline & & 6 & 62.59 & 71.73 & 71.1 & -8.51 & & & 6.1 \\
\hline & High & 3 & 64.04 & 67.49 & 64.9 & -0.86 & & & \\
\hline & & 4 & 55.54 & 59.66 & 57.5 & -1.96 & & & \\
\hline & & 6 & 62.59 & 66.99 & 65 & -2.41 & & & \\
\hline \multirow[t]{6}{*}{ Vowel } & Low & 3 & 64.04 & 73.15 & 73 & -8.96 & 8.8 & & \\
\hline & & 4 & 55.54 & 67.28 & 67 & -11.46 & & 7.6 & \\
\hline & & 6 & 62.59 & 74.72 & 74.4 & -11.81 & & & 5.3 \\
\hline & High & 3 & 64.04 & 67.15 & 64.2 & -0.16 & & & \\
\hline & & 4 & 55.54 & 60.89 & 59.4 & -3.86 & & & \\
\hline & & 6 & 62.59 & 70 & 69.1 & -6.51 & & & \\
\hline \multirow[t]{6}{*}[\int^{w}]{} & Low & 3 & 64.04 & 70.36 & 69.2 & -5.16 & 13.8 & & \\
\hline & & 4 & 55.54 & 59.45 & 57.2 & -1.66 & & 4.1 & \\
\hline & & 6 & 62.59 & 69.13 & 68 & -5.41 & & & 3.2 \\
\hline & High & 3 & 64.04 & 64.6 & 55.4 & 8.64 & & & \\
\hline & & 4 & 55.54 & 57.5 & 53.1 & 2.44 & & & \\
\hline & & 6 & 62.59 & 66.84 & 64.8 & -2.21 & & & \\
\hline
\end{tabular}

overall level $(-5.41$ to -1.66$)$ and in terms of variability $(3.8 \mathrm{~dB})$, the production of $\left[\int^{\mathrm{w}}\right]$ at the high SNR was less effective and more variable. As a result, $\left[\int^{\mathrm{w}}\right]$ in the high SNR was the only masker that had positive SNRs in two concerts (8.64 and 2.44) and also had a substantially larger range of SNRs (a $10.9 \mathrm{~dB}$ range, from -2.21 to 8.64). This in turn led to more variable changes in SNRs between the two SNR conditions [3.2 to 13.8 , see $\Delta$ SNR (dB) column]. The impact of these acoustic differences on intelligibility are discussed in Sec. IV.

\section{DISCUSSION}

This study asked whether non-phonetic factors that affect intelligibility of spoken words have similar effects on sung word intelligibility, and how reliable any such effects are in live performances. First, the literature leads us to expect speech and singing to be affected in parallel but not always identical ways, because singing differs from speech in many respects, including rhythmic distortion and changes in vowel timbre. Accordingly, we asked how intelligible our sung target words were and whether highly predictable final words are more intelligible than their less predictable counterparts, as is found for speech. The results confirm that the intelligibility of words in meaningful sentences sung solo in quiet can be very high, and that intelligibility must be cumulative over the course of a given sentence because more-predictable words were more intelligible than less-predictable ones, in both noise and quiet. Despite being performed in the slightly adverse listening conditions of a crowded concert hall (coughs, rustling), the observed values were close enough to free-field spoken word intelligibility to merit the interpretation that the melodies and the singer could successfully convey meaning. The main effect of SNR was also as predicted. These patterns validate the basic premises of the study and show that perception of spoken and sung words and sentences can be governed by similar factors, including the availability of both phonetic and semantic cues.

Of equal importance was the finding that the results were rather stable across concerts, despite stimuli being produced live in six different concert halls to self-selected audiences with different demographic characteristics. This variation in performance conditions contrasts starkly with how speech experiments are typically conducted, namely, using pre-recorded stimuli in well-controlled environments. Nevertheless, some differences between concerts did arise, and could have been caused by singer performance, venue, audience, or any combination. Our data suggest that differences between concerts were more likely to be due to differences between venues than between audiences because the audience characteristics Age and LS did not interact with Concert. In contrast, factors which might reasonably be expected to vary between concerts due to venue differences, such as Noise Type and SNR, did interact with Concert. Finally, any higher-level interactions with Concert could largely be attributed to the fact that the $\left[\int^{\mathrm{w}}\right]$, never a good masker, produced unreliable effects across concerts.

\section{A. Influences due to stimulus characteristics}

The three background noise types produced decreases in intelligibility in the expected order from $\left[\int^{\mathrm{w}}\right]$ to vowels to 
babble. The long-term average spectra support our interpretation that the intelligibility decrease for vowel and babble maskers compared with $\left[\int^{\mathrm{w}}\right]$ mainly reflects greater energetic masking of lower frequencies by vowels and babble. The difference in intelligibility between babble and vowel maskers may reflect differences in masking efficiency between the spectral envelopes of the two masker types: the babble masker's smooth spectral envelope may have led to more generalised masking compared to the much more localised masking effects of the prominences and troughs of the vowel masker's spectral envelope. This explanation would predict that energetic masking effects similar to that of spoken babble should be found if the vowel masker were sung on pitches that produced a smoother spectral envelope, either by using a wide variety and range of rapidly-changing pitches, or by choosing steady pitches whose combined harmonic spacing was relatively uniform. However, it must be noted that, due to the live performance contexts, differences between the masker noise types may have arisen not just with respect to spectral envelope, but also in terms of overall SNR and SNR range, real-time amplitude variation in the masker, and other unknown acoustic factors. For this reason, any interpretation of these effects must necessarily be tentative, as a combination of factors may drive the effect in any given situation.

SNR affected intelligibility both overall and as part of interactions. The overall effect was as expected, including in view of the acoustic measurements taken during the concerts (Table IX), which showed consistent differences between the high and low SNR conditions of at least $3 \mathrm{~dB}$ for the $\left[\int^{\mathrm{w}}\right]$ masker and $5 \mathrm{~dB}$ for the babble and vowel maskers. More interesting are potential interactions between SNR and variables such as Noise Type and Predictability, both of which are discussed in turn.

The SNR by Noise Type interaction reflected two independent influences: the weak and unreliable energetic masking potential of naturally-produced $\left[\int^{\mathrm{w}}\right]$ and the effect of SNR on informational masking. Responses were only influenced by SNR in vowel and babble maskers but not in the $\left[\int^{\mathrm{w}}\right]$ masker, where participants performed well at both SNRs. The lack of effect for the $\left[\int^{\mathrm{w}}\right]$ masker was expected in that $\left[\int^{\mathrm{w}}\right]$ lacks energy in the important frequency range below $2 \mathrm{kHz}$, and its amplitude was not as effectively raised as that for sung vowels or speech. Consequently, overall SNRs were higher for the $\left[\int^{\mathrm{w}}\right]$ masker than for the babble and vowel masker (Table IX). Turning now to informational masking, we suggest that it was more influential at lower SNRs when the signal was less clear. In high SNR conditions, intelligibility was comparable for vowel and babble maskers [see Fig. 5(B)], consistent with the acoustic measurements (see Estimated SNR column in Table IX). Conversely, at low SNRs, intelligibility was lower in babble than in the vowel masker despite estimated SNRs being consistently higher (better) in babble than the vowel masker. Part of this result pattern may be explained by the differing spectral properties of the babble and sung vowels providing different degrees of energetic masking, but informational masking was probably the main determinant of the observed differences between the effects of the two types of masker. At low SNRs, words and phrases could sometimes be discerned from the babble but not, of course, from the vowel masker. At high SNRs, negligible informational masking presumably occurred because the babble masker was too soft for individual words and phrases to be easily heard.

We did not find support for a SNR $\times$ Predictability interaction even though some laboratory-based studies have found smaller differences between high- and low-predictability sentences for high SNRs than low SNRs (Obler et al., 1985; Pichora-Fuller et al., 1995). The lack of effect may have occurred because there was a closed response set, together, perhaps, with the task being always challenging enough for listeners to benefit from sentential context.

The interaction between Noise Type and Predictability was largely driven by the lack of a predictability effect in the vowel masker compared with highly significant effects for both the $\left[\int^{\mathrm{w}}\right]$ and spoken babble maskers. The lack of predictability effect in the vowel masker condition occurred because intelligibility was not reduced for low-predictability sentences, in contrast to the other two masker conditions. In these other two conditions (babble and $\left[\int^{\mathrm{w}}\right]$ ), intelligibility for HP sentences was overall higher than for LP sentences. But it was not only the overall difference between HP and LP sentences that set the vowel masker apart; it was also the consistency of the effect. The predictability effect was much more consistent across concerts for the babble than the vowel masker [Fig. 6(B)] and did not seem to co-vary with demographic or venue conditions (Fig. 3 and Table II) for the babble masker. This is interesting because acoustically the vowel masker led to higher estimates of noise level than the babble masker (Table IX) and thus to more adverse SNRs. As a result one may have expected the adverse effect of the vowel masker to be particularly strong when no other cue, such as semantic predictability, was available to compensate for the acoustic degradation. However, as noted, this was not found: LP and HP target words were essentially equally intelligible in the presence of the vowel masker. An alternative interpretation for this result pattern could be that the babble contributed more informational masking. This in turn may be partly connected with the fact that the babble and vowel maskers contrast in the occurrence of acoustic discontinuities due to silences and aperiodicity in the babble, which in particular affect relative envelope amplitudes and $f 0$ continuity. Whereas such acoustic discontinuities are common in babble, there were no such discontinuities in the vowel maskers. Recent work on sung words shows these discontinuities increase intelligibility (Hawkins et al., 2015). Therefore the acoustic composition of the babble may make it harder for listeners to stream it out, possibly due to its increased intelligibility.

\section{B. Listener properties}

Age effects were largely as predicted and in line with laboratory-based speech research (Pichora-Fuller et al., 1995; Cervera et al., 2009): in quiet, the performance of the oldest age group was comparable to that of the other groups; over all noise conditions, the oldest age group made significantly more errors than the younger groups. In contrast with 
some research (Pichora-Fuller et al., 1995), but in line with others (Gordon-Salant and Fitzgibbons, 1997), we found no interaction between Predictability and Age: all age groups benefitted equally from an increase in sentence predictability in these conditions.

We did, however, find an Age $\times$ Noise Type interaction, caused primarily by the older listeners' $(40+)$ difficulty with the vowel masker: their performance was significantly worse than that of the other groups in vowels, and comparable to that of the other groups in babble. This could be due to the fact that the vowel masker had the lowest SNR of all maskers. If acoustic factors such as overall SNR played a particularly important role for older listeners, then the adverse SNR of the vowel masker could have had a greater influence for this age group than the adverse informational masking from the more semantically-rich babble.

Non-native English speakers performed less accurately overall than native English speakers, and derived less benefit from sentence context. The masker noises selectively prevented non-native speakers from effectively using higherlevel linguistic information to improve intelligibility in high-predictability sentences. These results are in line with laboratory-based speech research (Lecumberri et al., 2010; Mattys et al., 2010) and suggest that the types of masking we used had similar effects to those typically used in the laboratory. That non-native listeners derived less benefit than native listeners from sentence context suggests that the challenges of understanding sung text slowed non-native processing down, or encouraged non-native listeners to focus only on the end of the sentence. Both processes accord with conclusions drawn by Bradlow and Alexander (2007) that non-native listeners require enhanced signal clarity in order to take advantage of contextual information of the sort that distinguishes our highly-predictable target words from their low-predictability matches. Sung words are typically less intelligible than spoken words read from a text, and in any case non-native listeners do not necessarily benefit from efforts to clarify spoken or sung words, presumably due to limited experience with the culture- and language-specific strategies such efforts entail (Bradlow and Bent, 2002). A strategy of focussing mainly on the target word is the opposite of that suggested above to explain the lack of a predictability $\times$ SNR interaction-namely, that the challenging nature of the task caused listeners to focus on and hence benefit reliably from sentential context-but that explanation applied mainly to native listeners, whereas this one is restricted to the special group of non-native listeners.

There were no main or interacting effects of formal general musical training. This contrasts with findings that experienced (trained) singers understand sung text better than untrained listeners do, especially when the text is meaningless (Fine et al., 2009; Ginsborg et al., 2011), and that musicians' memory for sung texts may be superior to that of non-musicians (Kilgour et al., 2000). Methodological differences between these studies and ours probably explain part of the difference in results: our 4-alternative forced-choice task relied relatively little on memory, and entailed a constrained scoring system (words correct), whereas Fine et al. (2009) and Ginsborg et al. (2011) used free response and a fine-grained scoring system which partially reflected phonemes correct rather than entire words correct. Another reason for the lack of effect of Musical Training on intelligibility in the current study may be that, due to time constraints in the concerts, we asked only about any musical training, not singing per se. While singing experience enhances abilities to understand sung text, more general musical training may not. Finally, people who choose to attend concerts like ours, even if they have little formal musical training, may be very experienced in listening to sung text. This experience might enhance skills such that they perform at a level more like that of a musically-trained group that includes experienced singers (Bonnel et al., 2001; Bigand and Poulin-Charronnat, 2006).

\section{CONCLUSION}

This study investigated whether intelligibility of Western-style classical singing can be subject to the same influences as are found for speech in well-controlled laboratory experiments, despite the differences in production between the two and despite the fact that stimulus production and presentation was necessarily less well-controlled than in traditional listening experiments. Live presentations were chosen for two reasons. From a practical viewpoint, we wanted to make these experiments relevant to composers and musicians who often work in live performance situations. From a theoretical viewpoint, we wanted to examine how robust results were across different performances, venues, and audiences. The results suggest that many findings from speech research are applicable to singing under these circumstances, at least when general listening conditions are modelled to be reasonably similar to those experienced by listeners participating in laboratory-based speech intelligibility tests. In particular, manipulations related to energetic versus informational masking, masker noise level, target word predictability, listener age, and native language produced similar results to those found in canonical speech research. Our results also indicate that these effects are fairly robust, repeatedly emerging despite differences in live performances, venues, and audiences. These results may therefore be of considerable interest and practical value to musicians, choir directors, and composers engaged in this style of music who wish to manipulate or maximise text intelligibility in sung performances. The results are also of value to speech scientists interested in the generality of the principles underlying intelligibility, because they suggest that non-phonetic factors such as masker type, SNR, semantic predictability, listener age, and LS extend to sung text, and robustly and reliably affect intelligibility across a wide variety of listening situations, at least for the carefully-controlled, relatively simple music of the current study.

\section{ACKNOWLEDGMENTS}

We thank Dr. Edward Wickham for bringing together the diverse group essential to this collaborative work combining live music performance with controlled experimentation: a composer, professional singers, and speech scientists. Christopher Fox wrote the score and the vocal ensemble, The Clerks, sang with scientific rigour as 
well as beauty. We thank the audiences who took part with such good humour, and The Wellcome Trust for funding (Large Arts Award Tales from Babel).

${ }^{1}$ See supplementary material at http://dx.doi.org/10.1121/1.4929901 for (a) audio examples of the four sentences referenced in Fig. 2, and (b) additional information on factors included in and excluded from the models at each stage of the analysis.

Benolken, M. S., and Swanson, C. E. (1990). "The effect of pitch-related changes on the perception of sung vowels," J. Acoust. Soc. Am. 87, $1781-1785$.

Bigand, E., and Poulin-Charronnat, B. (2006). "Are we 'experienced listeners'? A review of the musical capacities that do not depend on formal musical training," Cognition 100, 100-130.

Bilger, R. C., Nuetzel, J. M., Rabinowitz, W. M., and Rzeczkowski, C. (1984). "Standardization of a test of speech perception in noise," J. Speech Hear. Res. 27, 32-48.

Boersma, P., and Weenink, D. (2015). "Praat: Doing phonetics by computer" (Computer program), Version 5.4.09, http://www.praat.org/ (Last viewed April 15, 2015).

Bonnel, A.-M., Faita, F., Peretz, I., and Besson, M. (2001). "Divided attention between lyrics and tunes of operatic songs: Evidence for independent processing," Percept. Psychophys. 63, 1210-1213.

Bradlow, A. R., and Alexander, J. A. (2007). "Semantic and phonetic enhancements for speech-in-noise recognition by native and non-native listeners," J. Acoust. Soc. Am. 121, 2339-2349.

Bradlow, A. R., and Bent, T. (2002). "The clear speech effect for non-native listeners," J. Acoust. Soc. Am. 112, 272-284.

Brungart, D. S. (2001). "Informational and energetic masking effects in the perception of two simultaneous talkers," J. Acoust. Soc. Am. 109, 1101-1109.

Burleson, R. (1992). "Functional relationships of language and music: The two-profile view of text disposition," La Linguistique 28, 49-63.

Carlsson, G., and Sundberg, J. (1992). "Formant frequency tuning in singing," J. Voice 6, 256-260.

Cervera, T. C., Soler, M. J., Dasi, C., and Ruiz, J. C. (2009). "Speech recognition and working memory capacity in young-elderly listeners: Effects of hearing sensitivity," Can. J. Exp. Psychol. 63, 216-226.

Cherry, E. C. (1953). "Some experiments on the recognition of speech, with one and with two ears," J. Acoust. Soc. Am. 25, 975-979.

Clopper, C. G., Pisoni, D. B., and Tierney, A. T. (2006). "Effects of openset and closed-set task demands on spoken word recognition," J. Am. Acad. Audiol. 17, 331-349.

Collister, L., and Huron, D. (2008). "Comparison of word intelligibility in spoken and sung phrases,” Emp. Musicol. Rev. 3, 109-125.

Fine, P., Ginsborg, J., and Barlow, C. (2009). "The influence of listeners' singing experience and the number of singers on the understanding of sung text," in Proceedings of the International Symposium on Performance Science, edited by A. Williamon, S. Pretty, and R. Buck (European Association of Conservatoires, Utrecht, The Netherlands), pp. $51-56$.

Ginsborg, J., Fine, P., and Barlow, C. (2011). "Have we made ourselves clear? Singers and non-singers' perceptions of the intelligibility of sung text," in International Symposium on Performance Science, edited by D. E. A. Williamon and L. Bartel [European Association of Conservatoires (AEC), Toronto, Canada], pp. 111-116.

Gordon-Salant, S., and Fitzgibbons, P. J. (1997). "Selected cognitive factors and speech recognition performance among young and elderly listeners," J. Speech, Lang., Hear. Res. 40, 423-431.

Gregg, J. W., and Scherer, R. C. (2006). "Vowel intelligibility in classical singing," J. Voice 20, 198-210.

Hawkins, S., Honey, K., Knight, S., and Heinrich, A. (2015). "Intelligibility of sung words in polytextual settings," in International Congress of Phonetic Sciences (Glasgow, United Kingdom).

Heinrich, A., Bruhn, K., and Hawkins, S. (2011). "Young and old listeners' perception of speech in the background of English- and foreign-accented babble," in Fechner Day 2011: International Society for Psychophysics Twenty-Seventh Annual Meeting, edited by D. Algom, D. Zakay, E.
Chajut, S. Shaki, Y. Mama, and V. Shakuf (International Society for Psychophysics, Herzeliya, Israel), pp. 113-118.

Hoen, M., Meunier, F., Grataloup, C.-L., Pellegrino, F., Grimault, N., Perrin, F., Perrot, X., and Collet, L. (2007). "Phonetic and lexical interferences in informational masking during speech-in-speech comprehension," Speech Commun. 49, 905-916.

Hollien, H., Mendes-Schwartz, A. P., and Nielsen, K. (2000). "Perceptual confusions of high-pitched sung vowels," J. Voice 14, 287-298.

Holm, S. (1979). "A simple sequentially rejective multiple test procedure," Scand. J. Stat. 6, 65-70.

Johnson, R., Huron, D., and Collister, L. (2014). "Music and lyrics interactions and their influence on recognition of sung words: An investigation of word frequency, rhyme, metric stress, vocal timbre, melisma, and repetition priming," Emp. Musicol. Rev. 9, 2-20.

Joliveau, E., Smith, J., and Wolfe, J. (2004). "Acoustics: Tuning of vocal tract resonance by sopranos,” Nature 427(6970), 116-116.

Kalikow, D., Stevens, K., and Elliott, L. (1977). "Development of a test of speech intelligibility in noise using sentence materials with controlled word predictability," J. Acoust. Soc. Am. 61, 1337-1351.

Kidd, G., Mason, C. R., Rohtla, T. L., and Deliwala, P. S. (1998). "Release from masking due to spatial separation of sources in the identification of nonspeech auditory patterns," J. Acoust. Soc. Am. 104, 422-431.

Kilgour, A. R., Jakobson, L. S., and Cuddy, L. L. (2000). "Music training and rate of presentation as mediators of text and song recall," Mem. Cognition 28, 700-710.

Lecumberri, M. G., Cooke, M., and Cutler, A. (2010). "Non-native speech perception in adverse conditions: A review," Speech Commun. 52, 864-886.

Lombard, E. (1911). "Le signe de l'elevation de la voix," Annals maladiers oreille, larynx, nez, pharynx 37, 101-119.

Mattys, S. L., Carroll, L. M., Li, C. K., and Chan, S. L. (2010). "Effects of energetic and informational masking on speech segmentation by native and non-native speakers," Speech Commun. 52, 887-899.

Mayo, L. H., Florentine, M., and Buus, S. (1997). "Age of second-language acquisition and perception of speech in noise," J. Speech, Lang., Hear. Res. 40, 686-693.

Miller, G. A., Heise, G. A., and Lichten, W. (1951). "The intelligibility of speech as a function of the context of the test materials," J. Exp. Psychol. 41, 329-335.

Moore, B. C. J., and Glasberg, B. R. (1983). "Suggested formulae for calculating auditory-filter bandwidths and excitation patterns," J. Acoust. Soc. Am. 74, 750-753.

Obler, L. K., Nicholas, M., Albert, M. L., and Woodward, S. (1985). "On comprehension across the adult lifespan," Cortex 21, 273-280.

Pichora-Fuller, M. K. (2003). "Processing speed and timing in aging adults: Psychoacoustics, speech perception, and comprehension," Int. J. Audiol. 42, 59-67.

Pichora-Fuller, M. K., Schneider, B. A., and Daneman, M. (1995). "How young and old adults listen to and remember speech in noise," J. Acoust. Soc. Am. 97, 593-608.

Rosen, S., Souza, P., Ekelund, C., and Majeed, A. A. (2013). "Listening to speech in a background of other talkers: Effects of talker number and noise vocoding," J. Acoust. Soc. Am. 133, 2431-2443.

Scotto di Carlo, N., and Germain, A. (1985). "A perceptual study of the influence of pitch on the intelligibility of sung vowels," Phonetica 42, 188-197.

Smith, J., and Wolfe, J. (2009). "Vowel-pitch matching in Wagner's operas: Implications for intelligibility and ease of singing," J. Acoust. Soc. Am. 125, EL196-EL201.

Sundberg, J. (1975). "Formant technique in a professional female singer," Acta Acust. Acust. 32, 89-96.

Tun, P. A., and Wingfield, A. (1999). "One voice too many: Adult age differences in language processing with different types of distracting sounds," J. Gerontol. B Psychol. 54B, P317-P327.

van Wijngaarden, S. J., Steeneken, H. J., and Houtgast, T. (2002). "Quantifying the intelligibility of speech in noise for non-native talkers," J. Acoust. Soc. Am. 112, 3004-3013.

Wilson, R. H., McArdle, R., Watts, K. L., and Smith, S. L. (2012). "The Revised Speech Perception in Noise Test (R-SPIN) in a multiple signal-tonoise ratio paradigm," J. Am. Acad. Audiol. 23, 590-605. 